\title{
$5-2019$
}

\section{Measuring the relative return contribution of risk factors}

Johan Knif

James W. Kolari

Gregory Koutmos

Fairfield University, GKoutmos@fairfield.edu

\section{Seppo Pynnönen}

Follow this and additional works at: https://digitalcommons.fairfield.edu/business-facultypubs Copyright (C) 2019, Springer Nature. All rights reserved. The post-print version has been archived here with permission from the copyright holder.

\section{Peer Reviewed}

\section{Repository Citation}

Knif, Johan; Kolari, James W.; Koutmos, Gregory; and Pynnönen, Seppo, "Measuring the relative return contribution of risk factors" (2019). Business Faculty Publications. 234.

https://digitalcommons.fairfield.edu/business-facultypubs/234

\section{Published Citation}

Knif, Johan, James W. Kolari, Gregory Koutmos, and Seppo Pynnönen. "Measuring the relative return contribution of risk factors." Journal of Asset Management 20, no. 4 (2019): 263-272. https://doi.org/10.1057/

s41260-019-00121-9

This item has been accepted for inclusion in DigitalCommons@Fairfield by an authorized administrator of DigitalCommons@Fairfield. It is brought to you by DigitalCommons@Fairfield with permission from the rightsholder(s) and is protected by copyright and/or related rights. You are free to use this item in any way that is permitted by the copyright and related rights legislation that applies to your use. For other uses, you need to obtain permission from the rights-holder(s) directly, unless additional rights are indicated by a Creative Commons license in the record and/or on the work itself. For more information, please contact digitalcommons@fairfield.edu. 
Published in the Journal of Asset Management vol 20, no. 4 (2019): 263-272.

\title{
Measuring the relative return contribution of risk factors
}

\author{
Johan Knif* \\ Hanken School of Economics \\ P.O. Box 287. FIN-65101 \\ Vaasa, Finland \\ Phone: +358 (0)50 5892612 \\ johan.knif@hanken.fi \\ James W. Kolari \\ JP Morgan Chase Professor of Finance \\ Texas A\&M University - Department of Finance \\ College Station, TX 77843-4218. USA \\ Phone: (979) 845-4803 \\ j-kolari@tamu.edu \\ Gregory Koutmos \\ Gerald M. Levin Endowed Chair in Finance \\ Fairfield University. Charles F. Dolan School of Business \\ Fairfield, CT 06430. USA \\ Phone: (203) 254-4000 x2832 \\ gkoutmos@fairfield.edu

\section{Seppo Pynnönen} \\ University of Vaasa \\ P.O. Box 700. FIN-65101 \\ Vaasa, Finland \\ Phone: +358 (0)6 3248259 \\ sjp@uwasa.fi
}




\begin{abstract}
This paper proposes a simple method to measure and compare the average relative return contribution of proposed risk factors. The method is applied to six common risk factors, including market, size, value, momentum, profitability, and investment, using 49 U.S. industry portfolios in the period 1969 to 2014 . We find that the average relative return contributions of the market factor and mispricing alpha are highest in all models and sample periods. When multifactors are included, their main effect is to reduce the contribution of the average market factor return with some reduction in the contribution of mispricing alpha.
\end{abstract}




\section{Introduction}

The theoretical development of the capital asset pricing model (CAPM) by Sharpe (1964), Lintner (1965a, 1965b), and Mossin (1966) ushered in a new era of empirical research on asset pricing models. The CAPM posits that the market portfolio located on the Markowitz (1952) efficient frontier can be utilized to measure the beta risk of assets that accounts for crosssectional variation in required rates of returns. Unfortunately, as surveyed by Fama and French (2004), extensive tests consistently reject the CAPM's prediction of a positive relation between beta and average stock returns. The failure of the market factor to adequately explain stock returns led to the exploration of other factors that might be useful (hereafter multifactors). Wellknown studies by Fama and French $(1992,1993$, and 1996) propose that the CAPM should be augmented with size and value factors. This three-factor model was augmented by Carhart (1997) using a momentum factor developed by Jegadeesh and Titman (1993). Recent work by Fama and French (2015) advanced a five-factor model using market, size, value, profitability, and investment factors. Other studies have proposed the usage of various macroeconomic factors. The growing list of multifactors naturally raises a number of questions. What are the relationships between different factors? How can the relative importance of different factors be evaluated? Regarding the latter, it is possible that their joint characteristics are more important than individual separate effects.

This paper proposes a new and intuitive measure of the contribution of individual risk factors to the required rate of return for a set of portfolios. To assess the average relative impact of each individual risk factor on the portfolio's required rate of return, we develop a novel metric dubbed the average relative absolute return contribution ARARC. This measure summarizes in percentage terms the average expected return contribution of each risk factor to the total 
expected return. As such, the ARARC offers asset managers a tool to monitor the relative impact of different risk factors on the expected return of a set of assets (portfolios). Standard regression tools such as t-values, and R-squares focus on explaining the variation of asset returns.

However, asset managers also need tools to evaluate what the relative impact of different risk factors on expected returns i.e., what factors should be used to minimize the impact of alpha returns. Thus, the ARARC can be used in conjunction with traditional measures to better evaluate the role of various risk factors.

Based on returns of 49 U.S. industry portfolios in the period July 1969 to December 2014, our empirical results show that major return contributions come from the market risk factor as well as the mispricing component, or alpha return, in the traditional market model. By comparison, the contributions of multifactors, such as size, value, momentum, profitability, and investment, are relatively smaller. Moreover, the average absolute return contribution of multifactors is partly overlapping with the market risk factor.

Our empirical results support the view that multifactors might not be separate risk factors but help to jointly in combination with a market index identify the market factor. According to this interpretation, previously conjectured by Shanken (1987) and Shanken and Weinstein (2006), the multifactors empirically compensate (to some extent) for poor single-factor proxies for the market portfolio. The Roll (1977) critique posits that the CAPM cannot be tested due to the inability to adequately proxy the market portfolio returns. In this regard, it is well known that equal- and value-weighted market indices have failed as market proxies to support the CAPM in empirical tests. We find that augmenting such single-factor indices with various multifactor portfolio returns tends to improve the overall fit of the asset pricing model. 
The paper is organized as follows. Section 2 presents a brief overview of relevant research. Section 3 presents the new measure for average relative risk factor return contribution. Section 4 describes the data. Section 5 reports the empirical findings. Section 6 gives the summary and conclusion.

\section{Literature review}

In a thorough review of the research on the cross-section of expected stock returns, Subrahmanyam (2010) concluded that, although more than 50 variables have been used to predict stock returns over the last 25 years, no consensus exists. He recommended further work to take into account the correlation among the variables and determine if the results survive simple variations in methodological approaches. Another review of major empirical findings by Jagannathan, Schaumburg and Zhou (2010) compared results using alternative econometric approaches (e.g., traditional regression versus GMM) with respect to both unconditional and conditional asset pricing models. An excellent overview of theory and evidence on the CAPM is provided by Fama and French (2004).

Research on multifactors accelerated after Fama and French's $(1992,1993)$ papers on the shortcomings of the CAPM and their now famous three-factor model. In light of earlier work by Basu (1977), Stattman (1980), Banz (1981), Rosenberg, Reid, and Lanstein (1985), and Bhandari (1988) on patterns in the cross-section of stock returns missed by market betas, Fama and French (1992, 1993) augmented the market factor with size and value (book-to-market equity) risk factors. The intuition is that the additional factors compensate for financial distress risk that is not fully captured by the market factor. This line of reasoning has been further explored by 
Amihud (2002), Griffin and Lemmon (2002), Arshanapalli, Fabozzi, and Nelson (2006),

Campbell, Hilscher, and Szilagyi (2008), and Simpson and Ramchander (2008).

Based on momentum findings identified by Jegadeesh and Titman (1993), Carhart (1997)

further augmented Fama and French's three-factor model by including a momentum factor (see also Grinblatt and Moskowitz, 2004). Subsequent studies have shown that momentum is both market dependent (see Chordia and Shivakumar, 2002 and Cooper, Gutierrez, and Hameed, 2004) and credit quality dependent (see Avramov, Chordia, Jostova, and Philipov, 2007).

It is possible that the market factor is comprised of a variety of risks. Hamada's (1972) famous corporate finance paper on capital structure shows that levered betas are a function of unlevered beta and risk associated with financial leverage. Merton's (1973) Intertemporal CAPM (ICAPM) hypothesizes that the market beta of a firm can be decomposed into two different parts, wherein one part stems from covariance with cash flows and the other part from covariance with discount rates. Campbell and Vuolteenaho (2004) empirically found that the former cash flow covariance is priced by the market. Armstrong, Knif, Kolari and Pynnönen (2012) demonstrated that market beta can be decomposed into a universal risk component with no exchange rate risk exposure and another component capturing the exchange rate risk of the asset. Perhaps multifactors are components of the market factor also. In this regard, some authors continue to support the CAPM and/or suggest that the augmented Fama-French factors might not be risk factors after all (Chan and Lakonishok, 1993; Grundy and Malkil, 1996; Daniel and Titman, 1996; Loughran, 1997; Griffin, Ji, and Martin, 2003; Tai, 2003; Petkova, 2006; Levy, 2009; Da, Guo and Jagannathan 2012; and Arnott, Hsu, Liu, and Markowitz, 2014).

Fama and French (2015) recommended a five-factor model containing market, size, value, profitability and investment as factors. They argued that this new model outperforms other 
asset pricing models and therefore should be used to obtain expected returns in practice. Fama and French (2016) presented supporting international empirical evidence for their five factormodel. Closely related to the five-factor model, Hou, Xue, and Zhang (2015) proposed a $q$-factor model including an investment and a profitability factor (return on equity). The studies by Fung and Hsieh (2004) and Ammann, Huber and Schmid (2010) have proposed seven-factor and eight-factor models, respectively. Other studies by Chan, Chen, and Hsieh (1985) and Chen, Roll, and Ross (1986) tested different sets of macroeconomic variables as factors in asset pricing (see also Cochrane (2011)).

A theoretical discussion of different asset pricing models is presented in Zhang (2015). French, $\mathrm{Wu}$, and $\mathrm{Li}$ (2016) studied the relative importance of stock characteristics for explaining stock returns. They evaluated the relative explanatory power of market, size, value, momentum, volatility, and liquidity factors for the U.K. market. Based on their relative contribution to the fit of the model and to the proportion of months the factor returns are statistically significant, the results indicated that momentum (liquidity) is the most (least) important factor.

In a recent study Fama and French (2018) use the maximum squared Sharpe ratio to rank the models. They also use the intercepts from the time series regression of left hand side portfolios on model factors. They also use the average squared alpha over the average squared return as a relative measure while making a distinction between nested and non-nested models. In this study we go a bit further. By using ARARC we are able to measure the relative impact of all factors included in the model, plus the important unwanted impact of the mispricing alpha. This way we can monitor the dynamics of the impact on ARARC as new tentative risk factors are included. We are not only comparing asset pricing models but also comparing the impact of individual risk factors within the same model. An added benefit is that this approach does not 
require that models are nested. In sum, the present study contributes to the ongoing discussion of factor contribution by proposing a simple method to measure and compare the average relative absolute return contribution of proposed risk factors.

\section{Methodology}

In line with Zhang (2005), Ang and Chen (2007), and Adrian and Franzoni (2009), we specify the conditional CAPM model such that the expected return on an asset is proportional to the conditional market factor loading and the corresponding conditional market factor risk premium,

or

$$
E_{t-1}\left[r_{i, t}^{e}\right]=E_{t-1}\left[\beta_{i, t}\right] E_{t-1}\left[r_{m, t}^{e}\right]
$$

where $r_{i, t}^{e}$ denotes the excess return on asset $i, i=1, \ldots, N, \beta_{i, t}$ is the market factor loading for asset $i$, and $E_{t-1}\left[r_{m, t}^{e}\right]$ is the corresponding conditional market risk premium. The conditional market factor loading (beta) is defined as

$$
\beta_{i, t \mid t-1}=E_{t-1}\left[\beta_{i, t}\right]=\operatorname{cov}_{t-1}\left(r_{i, t}^{e}, r_{m, t}^{e}\right) / \operatorname{var}_{t-1}\left(r_{m, t}^{e}\right)
$$

An empirical version of the conditional CAPM model will then take the form

$$
r_{i, t}^{e}=\alpha_{i, t}+\beta_{i, t} r_{m, t}^{e}+\varepsilon_{i, t}
$$

where $E_{t-1}\left[\alpha_{i, t}\right]=0$, and $\varepsilon_{i, t}$ are i.i.d. normal and uncorrelated with $r_{m, t}^{e}$. A corresponding empirical multifactor asset pricing model is given by

$$
r_{i, t}^{e}=\alpha_{i, t}+\sum_{k=1}^{K} \beta_{i, k, t} f_{k, t}+\varepsilon_{i, t}
$$

where again $\beta_{i, k, t}$ is the time-varying loading on factor $k, k=1, \ldots, K$, and $f_{k, t}$ is the corresponding value of the risk factor at time $t$. Of course, when the factors are uncorrelated, the conditional factor loadings can be written in the form of equation (2). 
A traditional approach in evaluating the contribution of an individual factor is to utilize standardized slope coefficients which amounts to multiplying the regression coefficient by the standard deviations of the corresponding factor. This makes the standardized coefficient reflect the contribution of one standard deviation change of the factor on the dependent variable (c.f. Bali, Engle, and Murray 2016, p.96). While standardization makes the slope coefficients comparable, they reflect the contribution of the variability of the explanatory variable on the dependent variable. In asset pricing, like CAPM, the focus is in the relation of the expected return to the underlying risk factors rather than explaining variability in the returns. Accordingly, our aim is to propose a measure that captures each factor's contribution to the expected return/risk factor relationship.

Assuming that the factor loadings are stationary, linear regression will provide unbiased estimates of the unconditional expectation $E\left[\beta_{i, k, t}\right]$. Furthermore, according to the basic characteristics of linear regression, the average residual is equal to zero, and the linear regression will cross the averages of the dependent and independent variables. As a consequence, at the mean of factors, all asset pricing models estimated by linear regression deliver by definition the same expected excess return as the average sample excess return for the portfolio. Hence, at the mean all models have exactly the same expected excess return independently of which and how many factors are included. Putting it differently, the estimated single factor model in equation (3) and the estimated multifactor model in equation (4) will imply the same sample average for the left-hand variable. ${ }^{1}$ This provides a plausible benchmarking point for comparing the economic

\footnotetext{
${ }^{1}$ For example taking expectations and dividing by the expected return in equation (3) for each asset yields $\frac{E\left(r_{i, t}^{e}\right)}{E\left(r_{i, t}^{e}\right)}=\frac{\alpha_{i}}{E\left(r_{i, t}^{e}\right)}+\frac{\beta_{i} E\left(r_{m, t}^{e}\right)}{E\left(r_{i, t}^{e}\right)}=100 \%$. This decomposes the expected return into the part attributed to alpha and the part attributed to the market factor. A similar expected return decomposition can be applied to any multifactor model. When comparing across models we chose the one that minimizes the contribution of the alpha return.
} 
contribution of different individual as well as groups of risk factors in an asset pricing model of type (4).

Based on this mean benchmarking intuition, we propose a new measure of the individual economic contribution of a risk factor to the pricing of an asset. More specifically, we define the average relative absolute return contribution $(A R A R C)$ of a risk factor $k$ in a specific model $l$ as follows

$$
A R A R C_{k, l}=\frac{1}{N} \sum_{i=1}^{N} \frac{\left|E\left[\beta_{i, k, t, l}\right]\right| * E\left[f_{k, t}\right]}{\sum_{k=1}^{K}\left|E\left[\beta_{i, k, t, l}\right]\right| * E\left[f_{k, t}\right]} * 100
$$

where $K$ is the number of factors in model $l$, and $N$ is the number of assets or portfolios. In the empirical version, the unconditional $E\left[\beta_{i, k, t, l}\right]$ is substituted for the corresponding linear regression estimate, and the unconditional $E\left[f_{k, t}\right]$ is estimated using the total sample average. The absolute values will control for the confusing effect of some factors having positive and some negative loadings. The unconditional expected risk premium is assumed to be nonnegative. The mispricing $\alpha_{i, k, t, l}$ is treated as a loading with expected premium equal to one. $A R A R C$ can be interpreted as the average percentage absolute contribution of a risk factor to the excess required return on a portfolio in the sample of test assets. Thus, rather than focusing on a single asset, $A R A R C$ provides a convenient summary of the average return contribution of each risk factor over the whole sample of test assets. Also, the ARARC for a group of factors is simply derived as the sum of the individual $A R A R C$ s for the factors in the group.

\section{Data}

As recommended by Lewellen, Nagel, and Shanken (2010) and Grauer and Janmaat (2010), the present study does not use grouped portfolios based on size, value, or other potential risk factors. 
Instead we utilize exogenous industry portfolios to examine the relative return contribution of risk factors. Monthly returns for 49 U.S. industry portfolios are sampled over the time period July 1969 to December 2014. The analysis is also carried out at the industry portfolio level over three subperiods: July 1969 to December 1984, January 1985 to December 1999, and January 2000 to December 2014. We use the traditional market model with the market excess return as the single risk factor. The following multifactor models are investigated: Fama-French 3-factor model, Carhart 4-factor model, and Fama-French 5-factor model. The factors in these multifactor models are constructed as zero-investment portfolios with long-minus-short positions in portfolios with high and low values of the corresponding characteristics. ${ }^{2}$ Comparisons across the different models is valid even though not all of them are nested.

A summary of descriptive statistics for the six risk factors are presented in Table 1. The [Insert Table 1]

average return is positive for all risk factors. The corresponding average annual returns are $6.29 \%$ for the market, $2.30 \%$ for size, $4.41 \%$ for value, $8.34 \%$ for momentum, $3.54 \%$ for profitability, and $4.41 \%$ for the investment factor. These averages are significantly different from zero at a $5 \%$ level for all factors except for the size factor. The standard deviation, skewness, and kurtosis for the investment factor is low compared to the other factors. By contrast, skewness is high and negative for market and momentum factors but positive and high for size. Also, kurtosis is especially high for momentum and profitability.

The contemporaneous unconditional correlations between the six risk factors are reported in Table 2. Panel A shows that all multifactors are significantly correlated with the market factor and that all correlations with the market are negative except for size. The investment factor has

\footnotetext{
${ }^{2}$ The data sets are made obtained by Kenneth French at his website. http://mba.tuck.dartmouth.edu/pages/faculty/ken.french/data_library.html
} 
the strongest correlation of -0.40 with the market and is also highly correlated with the value factor, 0.71 . The value factor is significantly correlated with all other factors too. The profitability factor is contemporaneously correlated with all factors except for investment. However, the investment factor appears to be uncorrelated with momentum and profitability. These results suggest that none of the six risk factors carry $100 \%$ unique information. The information in the risk factors is overlapping for the most part. This issue is confirmed by the multiple correlations reported in Panel B of Table 2.

[Insert Table 2]

Multiple correlations are obtained using the positive square root of the HAC-OLS $R$ squares from a regression of each factor against the rest of the factors alternatively. The market factor shares information with both size, profitability and investment. Size shares information with market and profitability. The value factor contains joint information with momentum, profitability and investment. The information in momentum overlaps value and investment. The profitability factor appears to be connected to all other factors except momentum. Lastly, the investment factor is correlated with all factors except for size.

These empirical descriptive results suggest that, among these six risk factors, the investment factor contains the least unique individual information with a multiple correlation as high as 0.76 with the other five factors. Also, the multiple correlation for the value factor is high at 0.75 . For momentum the multiple correlation is lowest at 0.32 . For the market factor the multiple correlation equals to 0.50 , which indicates that about $25 \%$ of the information in market returns is shared with the other five risk factors. 


\section{Empirical results}

To evaluate the economic contributions of different risk factors as well as sets of risk factors, we assume that the conditional factor loadings are stationary and use linear regressions with $\operatorname{Garch}(1,1)$ volatilities to estimate the expected long-run level of the loading. We estimate four different asset pricing models: market model, Fama-French 3-factor model, Carhart 4-factor model, and Fama-French 5-factor model. At the sample average of the risk factors, all four models have exactly the same expected required return on the portfolio equal to the sample average return on the portfolio. Hence, at the sample average all four models are comparable, and the impact of the factors as well as mispricing, on the required return can be evaluated. The reported results are very robust with respect to alternative estimation methods, such as HACOLS or Egarch because the estimated factor loadings (coefficients) are unbiased and the estimated risk premium (the average return on the factor) is the same for all models.

Table 3 presents the average relative absolute excess-return contribution of the risk factors at the sample mean, or ARARC, for the four models. The results for the total sample period show that for the market model, on average, the relative return contribution is $77 \%$ for the market factor and as high as 23\% for mispricing alpha. For the Fama-French 3-factor model the relative influence of mispricing is slightly lower at $21 \%$, and the contribution of the market factor decreases to $63 \%$. However, the relative return contribution of the size and value factors are low at $7 \%$ and $10 \%$ respectively. The inclusion of the momentum factor in the Carhart 4factor model decreases the contribution of the market factor to $60 \%$ and the contribution of the mispricing alpha is lowest at $18 \%$, compared to the other three models. The relative return contribution of the momentum factor is $6 \%$. For the Fama-French 5 -factor model the return contribution of the market factor decreases to $52 \%$, and the impact of alpha is $19 \%$. The ARARC 
for size, value, profitability, and investment are $6 \%, 8 \%, 9 \%$, and $6 \%$ respectively. For the total sample period, the individual relative return contribution of the multifactors (size, value, momentum, profitability, and investment) is each under 10\%. In the Fama-French 3-factor model the joint average return contribution of multifactors is $17 \%$ compared to $22 \%$ in the Carhart 4 factor model and $29 \%$ in the Fama-French 5-factor model. Using the earlier argument that the best model is the one that explains most of the alpha return, we can say that the Carhart 4-factor model is superior followed by the Fama-French 5-factor model. It is significant however that across all models the market factor makes on average the highest contribution to average returns. This is important from a portfolio management point of view and it is robust across models. Related studies focus on the alpha reduction potential of risk factors and pay little attention to the relative factor contributions. The use of the ARARC allows comparison across factors as well. [Insert Table 3]

Turning to the results in the first subperiod July 1969 to December 1984, which includes the oil crisis in early 1970s and the Latin Americas Sovereign Debt Crisis in 1982, Table 4 shows that the return contribution of the mispricing is much higher than for the total sample period. For the market model, it is $48 \%$, which is considerably higher than the Carhart 4-factor model at $27 \%$. Additionally, the individual return contributions of the multifactors are now much higher and almost on par with the return contribution of the market factor. The profitability factor has the lowest relative return contribution at only about $6 \%$.

\section{[Insert Table 4]}

The second subperiod January 1985 to December 1999 includes the Savings and Loan crises in late 1980s, Stock Market Crash in 1987 (Black Monday), Financial Institutions Reform, Recovery and Enforcement Act in 1989, Junk Bond Crash in 1989, Tequila Crash in 1994, and 
Asian Crisis in 1997-1998. The results for this subperiod in Table 5 are quite different. The return contribution for the market factor is high at about $80 \%$ in the market model and $67 \%$ in the Fama-French 5-factor model. Again, the contribution of mispricing alpha is lowest for the Carhart 4-factor model at about $16 \%$. For this subperiod the contributions of the multifactors are low in all models, and especially so for the value factor which is at less than $0.15 \%$. [Insert Table 5]

The third subperiod January 2000 to December 2014 covers the Dotcom Bubble and its aftermath as well as the Global Financial Crisis of 2007-2008. The results for this subperiod in Table 6 are similar to those in the first subperiod July 1969 to December 1984 . The return contribution of the market factor is relatively lower and ranges from 53\% to $32 \%$ (i.e., lowest in the Fama-French 5-factor model). Also, the impact of mispricing alpha is lowest in the FamaFrench 5-factor model for this subperiod at about $20 \%$.

[Insert Table 6]

Generally, the contributions of different risk factors vary depending on the sample period in which the estimates of risk premiums (the average return on the risk factor) vary. As the subperiod is shortened, higher variation is expected. However, in our tests of 49 industry portfolios, the individual average relative return contributions of the market factor and mispricing alpha are highest in all models and over the total sample period as well as in all three subperiod. If multifactors are included, the reduction in average market factor return contribution can be as high as $50 \%$ (i.e., in the first subperiod). These results suggest that the role of multifactors in the asset pricing model, from a return contribution point of view, is mostly to subsume the role of the market factor rather than to explain mispricing. This insight supports the 
views of Daniel and Titman (1997), Griffin, Ji, and Martin (2003), Tai (2003), and Petkova (2006), who conjecture that the augmented multifactors might not be separate risk factors.

Our findings that the market factor and the mispricing factor (alpha) are the most important in explaining average returns provides useful guidance in managing portfolios. From a portfolio management point of view the implication of these findings is that exposure to the market factor is the most significant contributor to the risk premium. Equally important, the resilience of the mispricing factor alpha, suggests that there is ample room for active management. This conclusion depends on the assumption that the relationship between asst returns and risk factors is linear and that the model on which alpha is based is correctly specified.

\section{Summary and conclusion}

This paper proposed a new average relative absolute return contribution measure (ARARC) to evaluate the average impact of a risk factor on required rates of return. Using several models we assess the return impacts of six popular risk factors as well as the return contribution of the mispricing component of the asset pricing model, the so-called alpha-return. The asset pricing models considered are the market factor in the traditional CAPM market model, the 3-factor Fama and French model that augments the CAPM with the size and value factors, the 4-factor Carhart model that additionally augments the model with the momentum factor, and the 5-factor Fama-French model that includes profitability and an investment factors.

Based on monthly returns for 49 U.S. industry portfolios from July 1969 to December 2014, our empirical results showed that major return contributions come from the market risk factor as well as the mispricing component. The effect of multifactors, such as size, value, momentum, profitability, and investment, is to decrease the individual return contribution of the 
market factor to a greater extent than to reduce the effect of the mispricing. The average relative absolute return contributions of multifactors partly overlap with the contribution of the market risk factor. The individual average relative return contributions of both the market factor and mispricing alpha are highest in all models over the total sample period as well as in all three subperiods. If multifactors are included, the reduction in contribution of average market factor return can be as high as $50 \%$. We conclude from these findings that multifactors help to jointly in combination with a market index identify the true market factor. 


\section{References}

Adrian, T, and Franzoni, F.,2009. Learning about beta: Time-varying factor loadings, expected returns, and the conditional CAPM. Journal of Empirical Finance 16, 537-556.

Amihud, Y., 2002. Illiquidity and stock returns: Cross-section and time-series effects. Journal of Financial Markets 5, 31-56.

Ammann, M., Huber, O., Schmid, M.,2010. Benchmarking hedge funds: The choice of factor model. SSRN Working paper, Electronic copy available at: http://ssrn.com/abstract=1672543

Ang, A, Chen, J., 2007. CAPM over the long run: 1926-2001. Journal of Empirical Finance 14, 1-40.

Armstrong, W., Knif, J., Kolari, J., Pynnönen, S., 2012. Exchange risk and universal returns: A test of international arbitrage pricing theory. Pacific-Basin Finance Journal 20, 24-40.

Arnott, R., Hsu, J., Liu, J., Markowitz, H., 2014. Can noise create the size and value effects? Management Science 61(11), 2569-2579.

Arshanapalli, B., Fabozzi, F.J., Nelson, W., 2006. The value, size, and momentum spread during distressed economic periods. Finance Research Letters 3, 244-252.

Avramov, D., Chordia, T., Jostova, G., Philipov, A., 2007. Momentum and credit rating. Journal of Finance 62, 2503-2520.

Bali, T.G., Engle, R.F., Murray, S., 2016. Empirical Asset Pricing: The Cross Section of Stock Returns. Hoboken, Wiley.

Banz, R.W., 1981. The relationship between return and market value of common stocks. Journal of Financial Economics 9, 3-18. 
Basu, S., 1977. The investment performance of common stocks in relation to their price-earnings ratios: A test of the efficient market hypothesis. Journal of Finance 32, 663-682.

Bhandari, L. C., 1988. Debt/equity ratio and expected common stock returns: Empirical evidence. Journal of Finance 43, 507-528.

Campbell, J., Hilscher, J., Szilagyi, J., 2008. In search of distress risk. Journal of Finance 63, 2899-2939.

Campbell, J., Vuolteenaho, T., 2004. Bad beta, good beta. American Economic Review 94, 1249-1275.

Carhart, M., 1997. On persistence in mutual fund performance. Journal of Finance 52, 57-82.

Chan, L., Lakonishok, J.,1993. Are the reports of beta's death premature? Journal of Portfolio Management 20, 51-62.

Chan, K.C., Chen, N., Hsieh, D., 1985. An exploratory investigation of the firm size effect. Journal of Financial Economics 14, 451--471.

Chen, N., Roll, R., Ross, S., 1986. Economic forces and the stock market. Journal of Business $59,383-403$.

Chordia, T., Shivakumar, L., 2002. Momentum, business cycle, and time-varying expected returns. Journal of Finance 57, 985-1019.

Cochrane, J. H., 2011. Discount rates. Journal of Finance 66, 1047-1108.

Cooper, M., Gutierrez, R., Hameed, A., 2004. Market states and momentum. Journal of Finance $59,1345-1365$.

Da, Z., Guo, R.-J., Jagannathan, R., 2012. CAPM for estimating the cost of equity capital: Interpreting the empirical evidence. Journal of Financial Economics 103, 204-220. 
Daniel, K., Titman, S., 1996. Evidence on the characteristics of cross sectional variation in stock returns. Journal of Finance 52, 1-33.

Fama, E. F., French, K.R., 1992. The cross-section of expected stock returns. Journal of Finance 47, 427-465.

Fama, E. F., French, K.R., 1993. Common risk factors in the returns on stocks and bonds. Journal of Financial Economics 33, 3-56.

Fama, E. F., French, K.R., 1996. Multifactor explanations of asset pricing anomalies. Journal of Finance 51, 55-84.

Fama, E.F., French, K. R., 2004. The capital asset pricing model: Theory and evidence. Journal of Economic Perspectives 18, 25-46.

Fama, E. F., French, K.R., 2015. A five-factor asset pricing model, Journal of Financial Economics 116, 1-22.

Fama, E. F., French, K.R., 2016. International tests of a five-factor asset pricing model, Journal of Financial Economics 123, 441-463

Fama, E.F.,French, K.R., 2018. Choosing factors, Journal of Financial Economics, 128, 234-252.

French, D., Wu Y., and Li Y. 2016. Identifying the relative importance of stock characteristics. Journal of Multinational Financial Management 34, 80-91.

Fung, W., Hsieh, D. A., 2004. Hedge fund benchmarks: A risk based approach. Financial Analysts Journal 60, 65-80.

Grauer, R. R., Janmaat, J. A., 2010. Cross-sectional tests of the CAPM and Fama-French three factor model. Journal of Banking and Finance 34, 457-470.

Grinblatt, M., Moskowitz, T., 2004. Predicting stock price movements from past returns: The role of consistency and tax-loss selling. Journal of Financial Economics 71, 541-579. 
Griffin, J., Lemmon, M., 2002. Book-to-market equity, distress risk, and stock returns. Journal of Finance 57, 2317-2336.

Griffin, J., Ji, S., Martin, S., 2003. Momentum investing and business cycle risk: Evidence from pole to pole. Journal of Finance 58, 2515-2547

Grundy, K., Malkiel, B.,1996. Reports of beta's death have been greatly exaggerated. Journal of Portfolio Management 2, 36-44.

Hamada, R.S., 1972. The effect of the firm's capital structure on the systematic risk of common stocks. Journal of Finance 27, 435-452.

Hou, K., Xue, C., and Zhang, L, 2015 Digesting anomalies: An investment approach, The Review of Financial Studies 28, 650-705.

Jagannathan, R., Schaumburg, E., Zhou, G., 2010. Cross-sectional asset pricing tests. Annual Review of Financial Economics 2, 49-74.

Jegadeesh, N., Titman, S.,1993. Returns to buying winners and selling losers: Implications for stock market efficiency. Journal of Finance 48, 65-92.

Levy, H., 2009. The CAPM is alive and well: A review and synthesis. European Financial Management 16, 43-71.

Lewellen, J., Nagel, S., Shanken, J., 2010. A skeptical appraisal of asset-pricing tests. Journal of Financial Economics 96, 175-194.

Lintner, J.,1965a. The valuation of risk assets and the selection of risky investments in stock portfolios and capital budgets. The Review of Economics and Statistics 47, 1, 12-37.

Lintner, J.,1965b. Security prices and maximal gains from diversification. Journal of Finance 20, 587-616. 
Loughran, T., 1997. Book-to-market across firm size, exchange, and seasonality: Is there an effect? Journal of Financial and Quantitative Analysis 32, 249-268.

Markowitz, H.,1952. Portfolio selection. Journal of Finance 7, 77-91.

Merton, R. C., 1973. An intertemporal capital asset pricing model. Econometrica 41, 867-887.

Mossin, J., 1966. Equilibrium in a capital asset market. Econometrica 34, 768-783.

Petkova, R., 2006. Do the Fama-French factors proxy for innovations in predictive variables? Journal of Finance 61, 581-612.

Roll, R., 1977. A critique of the asset pricing theory's tests' part I: On past and potential testability of the theory. Journal of Financial Economics 4, 129-176.

Rosenberg, B., Reid, K., Lanstein, R.,1985. Persuasive evidence of market inefficiency. Journal of Portfolio Management 11, 9-17.

Shanken, J., 1987. Multivariate proxies and asset pricing relations: Living with the Roll critique. Journal of Financial Economics 18, 91-110.

Shanken, J., Weinstein, M. I., 2006. Economic forces and the stock market revisited, Journal of Empirical Finance 13, 129-144.

Sharpe, W. F., 1964. Capital asset prices: A theory of market equilibrium under conditions of risk. Journal of Finance 19, 425-442.

Simpson, M.W., Ramchander, S., 2008. An inquiry into the economic fundamentals of the Fama and French equity factors. Journal of Empirical Finance 15, 801-815.

Stattman, D., 1980. Book values and stock returns. The Chicago MBA: A Journal of Selected Papers 4, 25-45. 
Subrahmanyam, A., 2010. The cross-section of expected stock returns: What have we learned from the past twenty-five years of research? European Financial Management 16, 1, 2010, $27-42$.

Tai, C.-S., 2003. Are Fama-French and momentum factors really priced? Journal of Multinational Financial Management 13, 359-384.

Zhang, L., 2005. The value premium. Journal of Finance 60, 67-103. 
Table 1 Summary of descriptive statistics for factors

\begin{tabular}{lrrrrrr}
\hline & & & & & & \\
& Market & Size & Value & Momentum & Profitability & Investment \\
\hline Mean & 0.51 & 0.19 & 0.36 & 0.67 & 0.29 & 0.36 \\
Median & 0.88 & 0.05 & 0.33 & 0.77 & 0.24 & 0.23 \\
Maximum & 16.10 & 19.18 & 13.91 & 18.38 & 12.19 & 9.51 \\
Minimum & -23.24 & -15.36 & -13.11 & -34.58 & -17.57 & -6.81 \\
Std. deviation & 4.60 & 3.09 & 2.98 & 4.39 & 2.20 & 2.02 \\
Skewness & -0.54 & 0.44 & -0.01 & -1.42 & -0.45 & 0.31 \\
Kurtosis & 4.78 & 6.87 & 5.49 & 13.79 & 14.14 & 4.55 \\
Jarque-Bera & 102.13 & 392.48 & 134.21 & 2783.81 & 2990.29 & 68.22 \\
Probability & 0.00 & 0.00 & 0.00 & 0.00 & 0.06 & 0.00 \\
Months & 546 & 546 & 546 & 546 & 546 & 546 \\
\hline
\end{tabular}

Monthly returns from July 1969 to December 2014. Data for risk factors are obtained from Kenneth French's website. 
Table 2 Unconditional correlation between risk factors

Panel A. Unconditional contemporaneous correlations

Bold indicates significance at the $5 \%$ level or less.

\begin{tabular}{lrrrrrr}
\hline & & & & & & \\
Factor & Market & Size & Value & Momentum & Profitability & Investment \\
\hline Market & 1.00 & & & & & \\
Size & $\mathbf{0 . 2 7}$ & 1.00 & & & & \\
Value & $\mathbf{- 0 . 3 2}$ & $\mathbf{- 0 . 1 3}$ & 1.00 & & & \\
Momentum & $\mathbf{- 0 . 1 5}$ & -0.06 & $\mathbf{- 0 . 1 5}$ & 1.00 & & \\
Profitability & $\mathbf{- 0 . 2 2}$ & $\mathbf{- 0 . 3 8}$ & $\mathbf{0 . 1 3}$ & $\mathbf{0 . 0 9}$ & 1.00 & 1.00 \\
Investment & $\mathbf{- 0 . 4 0}$ & $\mathbf{- 0 . 0 9}$ & $\mathbf{0 . 7 1}$ & 0.04 & -0.03 & \\
\hline
\end{tabular}

Panel B. Multiple correlations among factors

Estimates are obtained using the positive square root of HAC-OLS $R$-squares from a regression of the factor on a set of other factor.

\begin{tabular}{|c|c|c|c|c|c|c|c|c|}
\hline Factor & Coefficients & Market & Size & Value & Momentum & Profitability & Investment & $\begin{array}{l}\text { Square } \\
\text { root of } \\
R- \\
\text { squares }\end{array}$ \\
\hline Market & 0.95 & & 0.25 & -0.06 & -0.12 & -0.32 & -0.82 & 0.50 \\
\hline Size & 0.28 & 0.12 & & -0.02 & 0.00 & -0.48 & -0.03 & 0.43 \\
\hline Value & 0.01 & -0.01 & -0.01 & & -0.13 & 0.22 & 1.05 & 0.75 \\
\hline Momentum & 0.66 & -0.13 & 0.00 & -0.60 & & 0.25 & 0.60 & 0.32 \\
\hline Profitability & 0.39 & -0.08 & -0.23 & 0.22 & 0.05 & & -0.37 & 0.47 \\
\hline Investment & 0.25 & -0.09 & -0.01 & -0.47 & 0.06 & -0.17 & & 0.76 \\
\hline
\end{tabular}

Monthly returns from July 1969 to December 2014. Data for market, size, and momentum are obtained from Kenneth French's website 
Table 3: Average relative absolute excess-return contribution of risk factors at mean (ARARC) $\operatorname{Garch}(1,1)$ estimation

Total sample July 1969 to December 2014

\begin{tabular}{ccccc}
\hline ARARC & $\begin{array}{c}\text { Market } \\
\text { model }\end{array}$ & $\begin{array}{c}\text { French } \\
\text { 3-factor } \\
\text { model }\end{array}$ & $\begin{array}{c}\text { Carhart 4- } \\
\text { factor } \\
\text { model }\end{array}$ & $\begin{array}{c}\text { Fama } \\
\text { French 5- } \\
\text { factor } \\
\text { model }\end{array}$ \\
\hline Mispricing (alpha) & 22.84 & 20.59 & 18.35 & 18.77 \\
Market factor & 77.16 & 62.68 & 59.87 & 51.93 \\
Size factor & & 7.04 & 6.71 & 5.80 \\
Value factor & & 9.69 & 9.20 & 8.01 \\
Momentum factor & & & 5.87 & \\
Profitability factor & & & & 9.30 \\
Investment factor & & & & 6.19 \\
\hline Sum & 100.00 & 100.00 & 100.00 & 100.00 \\
\hline
\end{tabular}

Results are based on the Fama-French 49 industry portfolios using monthly returns from July 1969 to December 2014. Data for industry portfolios, market, size, and momentum, profitability, and investment are obtained from Kenneth French's website. The $A R A R C$ is calculated as

$$
\operatorname{ARARC}_{k, l}=\frac{1}{N} \sum_{i=1}^{N} \frac{\left|E\left[\beta_{i, k, l}\right]\right| * E\left[f_{k}\right]}{\sum_{k=1}^{K}\left|E\left[\beta_{i, k, l}\right]\right| * E\left[f_{k}\right]} * 100
$$

where $K$ is the number of factors in model $l$, and $N$ is the number of assets or portfolios. In the empirical version, the unconditional $E\left[\beta_{i, k, t}\right]$ is substituted with the corresponding regression estimate, and the unconditional $E\left[f_{k, t}\right]$ is estimated with the total sample average. 
Table 4: Average relative absolute excess-return contribution of risk factors at mean (ARARC) Garch(1,1) estimation

Total sample July 1969 to December 1984

\begin{tabular}{|c|c|c|c|c|}
\hline$A R A R C$ & Market model & $\begin{array}{c}\text { Fama- } \\
\text { French 3- } \\
\text { factor } \\
\text { model }\end{array}$ & $\begin{array}{l}\text { Carhart 4- } \\
\text { factor model }\end{array}$ & $\begin{array}{c}\text { Fama French } \\
\text { 5-factor model }\end{array}$ \\
\hline Mispricing (alpha) & 48.06 & 31.48 & 27.18 & 30.39 \\
\hline Market factor & 51.94 & 26.74 & 22.80 & 19.96 \\
\hline Size factor & & 19.68 & 17.79 & 14.87 \\
\hline Value factor & & 22.10 & 19.06 & 15.32 \\
\hline Momentum factor & & & 13.17 & \\
\hline Profitability factor & & & & 5.57 \\
\hline Investment factor & & & & 13.89 \\
\hline Sum & 100.00 & 100.00 & 100.00 & 100.00 \\
\hline
\end{tabular}

Results are based on the Fama-French 49 industry portfolios using monthly returns from July 1969 to December 1984. Data for industry portfolios, market, size, and momentum, profitability, and investment are obtained from Kenneth French's website. The ARARC is calculated as

$$
\operatorname{ARARC}_{k, l}=\frac{1}{N} \sum_{i=1}^{N} \frac{\left|E\left[\beta_{i, k, l}\right]\right| * E\left[f_{k}\right]}{\sum_{k=1}^{K}\left|E\left[\beta_{i, k, l}\right]\right| * E\left[f_{k}\right]} * 100,
$$

where $K$ is the number of factors in model $l$, and $N$ is the number of assets or portfolios. In the empirical version, the unconditional $E\left[\beta_{i, k, t}\right]$ is substituted with the corresponding regression estimate, and the unconditional $E\left[f_{k, t}\right]$ is estimated with the total sample average. 
Table 5: Average relative absolute excess-return contribution of risk factors at mean (ARARC) Garch(1,1) estimation

Total sample January 1985 to December 1999

\begin{tabular}{ccccc}
\hline ARARC & Market model & $\begin{array}{c}\text { Fama- } \\
\text { French 3- } \\
\text { factor } \\
\text { model }\end{array}$ & $\begin{array}{c}\text { Carhart 4- } \\
\text { factor model }\end{array}$ & $\begin{array}{c}\text { Fama French } \\
\text { 5-factor model }\end{array}$ \\
\hline Mispricing (alpha) & 20.22 & 17.13 & 15.79 & 18.37 \\
Market factor & 79.78 & 76.66 & 70.95 & 66.70 \\
Size factor & & 6.07 & 4.63 & 4.70 \\
Value factor & & 0.14 & 0.12 & 0.14 \\
Momentum factor & & & 8.51 & \\
Profitability factor & & & & 6.62 \\
Investment factor & & 100.00 & 100.00 & 3.48 \\
\hline Sum & 100.00 & & & 100.00 \\
\hline
\end{tabular}

Results are based on the Fama-French 49 industry portfolios using monthly returns from January 1985 to December 1999. Data for industry portfolios, market, size, and momentum, profitability, and investment are obtained from Kenneth French's website. The ARARC is calculated as

$$
\operatorname{ARARC}_{k, l}=\frac{1}{N} \sum_{i=1}^{N} \frac{\left|E\left[\beta_{i, k, l}\right]\right| * E\left[f_{k}\right]}{\sum_{k=1}^{K}\left|E\left[\beta_{i, k, l}\right]\right| * E\left[f_{k}\right]} * 100
$$

where $K$ is the number of factors in model $l$, and $N$ is the number of assets or portfolios. In the empirical version, the unconditional $E\left[\beta_{i, k, t}\right]$ is substituted with the corresponding regression estimate, and the unconditional $E\left[f_{k, t}\right]$ is estimated with the total sample average. 
Table 6: Average relative absolute excess-return contribution of risk factors at mean (ARARC) Garch(1,1) estimation

Total sample January 2000 to December 2014

\begin{tabular}{ccccc}
\hline AARC & Market model & $\begin{array}{c}\text { Fama- } \\
\text { French 3- } \\
\text { factor } \\
\text { model }\end{array}$ & $\begin{array}{c}\text { Carhart 4- } \\
\text { factor model }\end{array}$ & $\begin{array}{c}\text { Fama French } \\
\text { 5-factor model }\end{array}$ \\
\hline Mispricing (alpha) & 46.54 & 30.68 & 30.03 & 19.67 \\
Market factor & 53.46 & 37.70 & 37.05 & 31.73 \\
Size factor & & 14.56 & 14.40 & 11.98 \\
Value factor & & 17.06 & 16.70 & 12.23 \\
Momentum factor & & & 1.82 & 13.29 \\
Profitability factor & & & & 11.10 \\
Investment factor & & 100.00 & 100.00 & 100.00 \\
\hline Sum & 100.00 & &
\end{tabular}

Results are based on the Fama-French 49 industry portfolios using monthly returns from January 2000 to December 2014. Data for industry portfolios, market, size, and momentum, profitability, and investment are obtained from Kenneth French's website. The $A R A R C$ is calculated as

$$
\operatorname{ARARC}_{k, l}=\frac{1}{N} \sum_{i=1}^{N} \frac{\left|E\left[\beta_{i, k, l}\right]\right| * E\left[f_{k}\right]}{\sum_{k=1}^{K}\left|E\left[\beta_{i, k, l}\right]\right| * E\left[f_{k}\right]} * 100
$$

where $K$ is the number of factors in model $l$, and $N$ is the number of assets or portfolios. In the empirical version, the unconditional $E\left[\beta_{i, k, t}\right]$ is substituted with the corresponding regression estimate, and the unconditional $E\left[f_{k, t}\right]$ is estimated with the total sample average. 